\title{
Listening Skill Requires a Further Look into Second/Foreign Language Learning
}

\author{
Hossein Bozorgian \\ Faculty of Education, Queensland University of Technology, Brisbane, QLD 4059, Australia \\ Correspondence should be addressed to Hossein Bozorgian, h.bozorgian@qut.edu.au \\ Received 18 April 2012; Accepted 10 July 2012 \\ Academic Editors: N. Dumais and R. D. Tennyson \\ Copyright () 2012 Hossein Bozorgian. This is an open access article distributed under the Creative Commons Attribution License, \\ which permits unrestricted use, distribution, and reproduction in any medium, provided the original work is properly cited. \\ Current English-as-a-second and foreign-language (ESL/EFL) research has encouraged to treat each communicative macroskill \\ separately due to space constraint, but the interrelationship among these skills (listening, speaking, reading, and writing) is not \\ paid due attention. This study attempts to examine first the existing relationship among the four dominant skills, second the \\ potential impact of reading background on the overall language proficiency, and finally the relationship between listening and \\ overall language proficiency as listening is considered an overlooked/passive skill in the pedagogy of the second/foreign language \\ classroom. However, the literature in language learning has revealed that listening skill has salient importance in both first and \\ second language learning. The purpose of this study is to investigate the role of each of four skills in EFL learning and their existing \\ interrelationships in an EFL setting. The outcome of 701 Iranian applicants undertaking International English Language Testing \\ System (IELTS) in Tehran demonstrates that all communicative macroskills have varied correlations from moderate (reading \\ and writing) to high (listening and reading). The findings also show that the applicants' reading history assisted them in better \\ performing at high stakes tests, and what is more, listening skill was strongly correlated with the overall language proficiency.
}

\section{Introduction}

The challenge in reference to ESL/EFL learning in applied linguistics is that the four communicative macroskills on the current published research, for example, reading [1], writing [2], speaking [3], and listening [4-6] are treated separately in second language learning. Recently, a study conducted by Hartley [7] examines the citation of recently reviewed articles published in applied linguistics and verifies the lack of overlap between references of studies focusing on the four communicative macroskills, despite listing one or two papers where the overlap occurs. One way of promoting such opportunities is to unpack the existing interwoven relationship among the communicative macroskills. This study thus attempts to find out the link among communicative macroskills and the relationship between listening and other skills as Hartley maintains that deciphering reading in first and second language relies on writing, in general, and thinking of speaking and listening, in particular. In this relation, a substantial amount of research has been conducted in reading and writing skills, whilst investigators
[8-10] have underscored the role of listening and speaking skills in human learning and development. The reason for inadequate attention to listening/speaking research is that the instruction of listening and speaking requires teaching pronunciation and cross-cultural pragmatics to understand a speaker's intended message (e.g., $[11,12])$.

Arguing for the role of listening in the communicative macroskills, Hunsaker [8] found that more than three quarters of what children learn in school is achieved through listening in the classroom. Closely aligned with this is the study conducted by Gilbert [13], which demonstrated the prominence of listening in schools. Gilbert found that K12 students spend between $65 \%$ and $90 \%$ of their school time in learning, which is achieved, in fact, through listening trajectory. Research has found that improvement in listening skill has a positive effect on other language skills: reading, writing, and speaking. To illustrate, Morris and Leavey [10] have conducted a study focusing on preschoolers' phonological development. The study reveals that listening skill instruction improves preschoolers' phonological awareness. Similarly, two other studies found out that listening skill 
instruction assists students in improving reading comprehension in middle school $[14,15]$. In addition, the outcome of Bergman's [15] study has revealed that listening and reading stories at the same time contribute to enhance reading comprehension. In addition to the impact of listening skill on reading comprehension, a study reported by Berninger [16] showed that students in grades 1-6 improve their spelling significantly through aural skill instruction, whereas there is a high correlation between grades $1-3$ and the improvement of narrative and expository composition in grades 2 and 3 through listening instruction.

The studies presented above show the multiple requirements of listening skill in learning first language, in general, with a particular focus on second language learning. Now that listening is crucial for human learning, it is worthwhile to explore the origin of this fundamental skill.

\section{The Essence of Listening Skill}

The essence of listening skill for effective communication has been recognized almost for a century. Rankin [17] conducted a study and found that listening skill was the most dominant skill for the mode of human communication. Listening skill occupies almost $50 \%$ of our daily communications. In this regard, two studies conducted by Ralph and Stevens [18] and Rankin [19] reported that listening $(46 \%)$, speaking $(30 \%)$, reading $(16 \%)$, and writing $(9 \%)$ involve our daily communication. However, there were no more similar studies until the 1940s. The base of listening inquiry was primarily laid academically in the late 1940s, and the founders (James Brown, Ralph Nichols, and Carl Weaver) of the listening skill were considered as the "fathers of listening" [20]. Listening skill was taken into the second and foreign language research field in the mid-20th century, and many researchers put listening as the focus of their studies. After half a century, a professional committee, the International Listening Association (ILA), was established in 1979 to develop listening skill [21]. Knowing how to entail listening instruction and assessment in the school syllabi was the main target of the pedagogy. Steven [22] pointed out that many studies provide a focus on either understanding listening comprehension or listening critically agreeing or disagreeing with oral input.

Listening skill varies as the context of communication differs. Wolvin and Carolyn [23] propose five different kinds of listening. First, discriminative listening helps listeners draw a distinction between facts and opinions. Second, comprehensive listening facilitates the understanding of oral input. Third, critical listening allows listeners to analyse the incoming message before accepting or rejecting it. Fourth, therapeutic listening serves as a sounding board and lacks any aspect of critiques. Finally, appreciative listening contributes listeners to enjoy input and receive emotional impressions. All the varieties of listening help to demonstrate that listening is an active process rather than a passive one. Wolvin and Coakley define the process of listening as making sense of oral input by attending to the message. Similarly, Floyed [24] defines listening as a process entailing hearing, attending to, understanding, evaluating, and responding to spoken messages. He further believes that listeners should be active participants in communication process. Thus, the second definition of listening is to understand the oral input mentioned by Wolvin and Coakley used as a tool in IELTS to evaluate applicants' listening.

As the studies reveal, listening comprehension lies at the heart of language learning, but it is the least understood and least researched skill in language learning, and the listening process is often disregarded by foreign and second language instructors [25]. Particularly, in a digital era, people around the globe are in spoken contact through a variety of digital platforms. These global technical communication progresses underline the importance of listening skill in our daily contacts. Acknowledging the fact that listening skill requires development, the professional committee ILA invited many experts in psychology, communication, counselling, education, political science, philosophy, business, law, and sociology to share their perspectives. Whilst the evidence gained displays a crucial contribution of listening virtually in all fields, the following section documents the existing relationship between listening and other communicative macroskills.

\section{Listening and Speaking Continuum}

There has been much debate about the effect of listening skill on speaking proficiency. Oral skill (speaking), like other language skills, deals with or combines different branches of learning initiatives. This explicit skill involves a repertoire of psychological and interpersonal features in terms of language production (syntax, semantics, and speech process) and the way they are developed [3]. Even though speaking skill involves a range of learning perspectives, listening skill manipulates human learning, by and large, and develops other language skills such as speaking to a large extent. Rost [26] proposed three reasons showing the essential role listening plays to improve speaking skill. First, spoken language provides a means of interaction for the learner. Because learners must interact to achieve understanding, access to speakers of the language is essential. Moreover, learners' failure to understand the language they hear is an impetus, not an obstacle, to interaction and learning. Second, authentic spoken language presents a challenge for the learner to attempt to understand the language as native speakers actually use it. Third, listening exercises provide teachers with the means for drawing learners' attention to new forms (vocabulary, grammar, and new interaction patterns) in the language. In addition to pursuing linguistic aspects in speaking, discourse also generates a number of general intentions-discussion initiatives, maintaining and terminating the discussion as efficiently as the aim of dialogue is met. It aligns with Bygate's [3] suggestions: (i) social perspective in speaking, (ii) oral discourse configuration, and (iii) content knowledge in speaking. The first dimension, social oral aspect entailing identity in second language (e.g., [27]) and formality, intends to maintain discussions in speaking. This dimension indeed is social in nature and supports Blommaert's [28] conceptualization of identity as semiotic potential and is in line with Lantolf and Thorn's 
[29] socio-cultural theory. The second dimension provides a focus on patterns of oral discourse, which is normally disparate across cultures (e.g., [30]). Finally, the crucial part of oral discussion is contingent on the knowledge of the content and topic (e.g., [31]) being discussed. A speaker can maintain the speech well on the track if enough knowledge of the topic is available. Therefore, cultural factors: identity, formality, knowledge of world, and topic and discourse patterns contribute to maintain conversation with a minimum cultural shock in cross-cultural contacts.

Returning to the critical association between listening and speaking, not only does listening comprehension precede speaking, it also develops more speedily than speaking. Listening is considered "offset hypothesis" [32] and related to this theory is students' reflection, "I understand everything you say, but I can't repeat it" (p. 31). James [32] emphasizes that listening must be paid due attention more advanced than speaking at the very lowest levels of speaking proficiency. Thus, it is no surprise to consider the close relationship between listening and speaking from reviewing the findings of the studies above.

\section{Listening and Reading Continuum}

Receptive skills, such as listening and reading, share basic cognitive processes, and they are, nonetheless, flooded in two disparate input sources. Observing a typical process in language learning, Pearson and Fielding [33] linked listening with reading skill. They argued that like reading, listening involves phonological, syntactic, and semantic orchestration of skill and the knowledge controlled by cognitive processes at the same time. Comparing listening and reading skills, Harris et al. [34] maintained that graphic skill (reading) is more approachable than aural skill (listening). The reason for this is that listeners lack any adequate control over the comprehension of speech trail, whereas in reading comprehension, readers go back to difficult words or phrases to assess their comprehension. Further, learning to read requires a complex visual system of a word, orthography, phonology, and semantics, whereas in listening, the stakes are higher in figuring out the oral input which is quick and temporary. Regardless of which language, oral language is already developed before the schooling period and thus precedes reading ability. It aligns with a theory suggesting that once a new written word is decoded phonologically, the link between phonology and semantics provides the meaning [35-37]. In addition to the central mutual comprehension between receptive skills, reading and listening, investigators such as Bae and Bachman [38], Park [39], Samuels [40], and Vandergrift $[41,42]$ in the field agree upon the following similarities of the two skills. First, both entail fundamental language process and world knowledge and are engaged in comprehension as well as decoding. Second, two main comprehension processes (bottom-up and top-down) used to make sense of the input are involved actively with the receptive skills (see also $[6,43]$ ). Third, perceiving receptive input demands a pliable cognitive process to revise cognitive representations in that both listeners and readers construct while receiving input (e.g., Williams and Lanvers, [44,
45]). Finally, other psychological factors, metacognition in listening $[4,46]$ and in reading (e.g., [47]) and motivation in reading and listening (e.g., $[48,49])$, affect receptive skills.

However, the discrepancy between listening and reading has not escaped researchers' attention (e.g., [50]). The critical dissimilarity of the two lies in the input access where a listener is not able to rehear the oral input whereas a reader rereads the text input back and forth when needed [51]. Related to this perspective, Brown [52] proposed the following issues of making distinctions between the two cognitive processing skills. First, a listener cannot assess incoming oral input as well as a reader does. Second, a listener has a limited memory capacity (see also [53]) to keep stream of information for integration in the oral input, whereas reading is a graphic skill, and graphics and symbols add more memory capacity for further deciphering the message in texts. Finally, a listener repeatedly associates the flow of input to one's background and prior knowledge (e.g., [54]).

Comparing listening with reading in terms of cognitive load processing, the complexity of deciphering oral input in listening is more than understanding text input in reading comprehension [55]. In this regard, Vandergrift [42] suggests a few likely reasons for the difference between receptive skills regarding the cognitive load process. First, listeners should make sense of oral linguistic features, different sounds and lexicon, as well as nonlinguistic and prosodic features, stress, intonation, and discourse (e.g., [56]) conveying essential elements of information. Second, a listener has little control over what is said, and due to its temporary and ephemeral process, the listener cannot review big chunks of oral input. Third, speaking is spontaneous, and hesitation, false starts, pauses, corrections, and short-term units are quite common in oral input; a listener should deal with unplanned situation at the same time. Finally, listening depends more on the situation and "socially coded acoustic cues" ([57], page. 136) than reading because it prepares the listener to associate the incoming speech with the world and background knowledge to perceive the message. These features highlight the significance of listening comprehension against reading comprehension. Despite the difference between listening and reading, Richards [58] and Brown [52] endorse a strong positive relationship between listening and reading span. The analysis of studies presents similarities of receptive skills: listening and the reading outweigh the dissimilarities. The following section deals with the commonality between listening and writing skills.

\section{Listening and Writing Continuum}

Writing skill, besides its cognitive process, requires mechanical attempts to initiate it, so children need to be cognitively and physically prepared to embrace this skill at school age. Oral/aural (listening and speaking) skills construct learning bricks and mortar (e.g., [25]) to build writing systems upon far sooner than reading skill. Secondary language skills, reading and writing, rely highly on the primary language skills, speaking and listening [16]. The reasons are (i) language acquisition begins with aural development at birth and oral 
at 12-18 months and (ii) reading orientation initiates at 60-84 months old and writing instruction at school age (e.g., [59, 60]). As aural/oral skills have already been the central focus of childhood, the writing instruction begins during school period. Very recently, a study conducted by Yalcinkaya et al. [61] shows that the foundation of receptive (reading) and expressive (writing) skills is built upon aural and oral skills. They argue that written language skills hardly develop without realizing the infrastructure of a languagethe sounds. They conclude that listening ability strongly influences speaking, reading, and writing ability. Contrary to this idea, Semel et al. [62] argue that a distinction is drawn between oral and written language but is not adequate nor is sufficiently documented between receptive language (processing language input) and expressive language (producing language output). However, some researchers [41, 63, 64] attribute poor listening to (a) inadequate attention to the auditory information, (b) inappropriate listening situations: distractions and noises, (c) difficulty to distinguish speech sounds, and (d) incompetence in recalling phonemes and manipulating them explicitly. Instruction of auditory skill contributes to the process of decoding of graphic images or sounds effectively because it is a sound giving meaning to the letter and graphic image [61].

The correlation between oral language development and writing is congruent. Returning to the relationship between listening and writing skills, Shanahan [59] argues that the theory of efficient writing relies on the structure of oral language development. Shanahan emphasizes that writing depends highly on linguistic perspectives such as phonological awareness, lexicons, morphemes, syntactic structures, discourse organizations, and pragmatics. Similarly, Berninger et al. [65] point out that aural/oral language instruction improves the acquisition of phonologicalorthographic mapping underlying spelling systems in that explicit strategy implication leads to learning consciousness and awareness.

This review of the research argues that limited evidence has been found in assessing the relationship between listening and other communicative macroskills in first language, at large and various listening effectiveness in second/foreign language learning, in particular. The paper also demonstrates that there are inadequate investigations focusing on the contributions of listening skill in the development of other language skills.

Afterward, having created these composite IELTS discrete and overall scores, I followed a correlation design to measure the relationship among communicative macroskills: listening, speaking, reading, and writing altogether.

\section{Research Questions}

The purpose of the current study is to examine (i) the relationship between listening, speaking, reading, and writing skills, (ii) the impact of reading background on the high stakes test performance, and (iii) whether listening is strongly correlated with overall language proficiency in IELTS. In particular, the research addresses the following questions.
(1) What is the relationship between communicative macroskills: listening, speaking, and reading and writing proficiency skills in IELTS?

(2) Does applicants' reading background help them make a difference in high stakes test (IELTS) compared with other skills?

(3) Does listening skill have a stronger correlation with the overall language proficiency than other skills in IELTS?

\section{Method}

7.1. Participants and Context. The participants in the study were 701 ESOL male and female applicants, with an age range of 24-37 in the capital of Iran, Tehran, who were planning for continuing their college education in an English speaking country. There were actually 746 applicants, but 45 declined to respond to the IELTS test completely and their responses were deleted due to the extreme scores. All applicants were Iranian speakers of Persian who were literate in their first language as evidenced by the courses they had passed at schools which lasted for twelve years. To test the research assumptions, all the applicants undertook the academic training IELTS. English language in Iran is not the primary language but a foreign language, which is taught as a school subject and has no acknowledgement out of school. Similarly, Nayar's [66] definition of English as a foreign language $(\mathrm{EFL})$ is in a situation where English language is taught in a school syllabus like other school subjects and has no application out of the school context. Thus, English reading, as a school subject, is taught traditionally, grammar translation method (GTM) in middle school and high school in Iran. All college students must pass 3-5 credits in English reading course depending on the specialized college course. All participants must have already gone through English reading instruction for six years.

In addition to applicants' English reading background during middle and high school and college, all of them learn English language in various language institutes throughout Iran. The basic goal in optimizing global language education is to meet learning requirements, and the main part of which is to revise the curriculum and equip learners with adequate knowledge. In this light, there has been a gradual shift from traditional grammar translational method (GTM) and audiolingual method (ALM) to communicative language teaching (CLT) so that learners enhance both linguistic knowledge and communication fluency in the target language. The prevailing pedagogy (CLT) has been implemented over the last decade virtually in all language institutes in Iran, as the development and expansion of what is commonly referred to as the "communicative approach" have served directly and indirectly to the findings of abundant research in applied linguistics over the past three decades (e.g., [12]).

7.2. Instrument. An academic training of International English Language Testing System (IELTS) was the only research instrument measuring the three research assumptions. IELTS provides a profile of an applicant's ability to use English 
language. Applicants receive scores on a band from 1 (nonuser) to 9 (expert user). Applicants receive a score for each test component: listening, reading, writing, and speaking. The individual scores are then averaged and rounded to produce an overall band Score. IELTS is available in two formats: academic and general training. All applicants took the same listening and speaking modules but different reading and writing modules. The academic version is for tertiary study for those who want to study or train in an English speaking university or tertiary institution. Admission for undergraduate and postgraduate courses is based on the results of the academic test scores. The general training format, for school, work, or migration, focuses on basic survival skills in a broad social and educational context. It is for those who are going to English speaking countries to do secondary education, work experience, or training programs. People migrating to Australia, Canada, and New Zealand must sit the general training test (http://www.ielts .org/institutions/test_format_and_results.aspx).

The validity and reliability of the international known test is determined conclusively due to the high demand of this test. In other words, a passing result in this test is indeed a door opening to all international applicants to be a college student in an English speaking country. Linked to this idea, over $1,000,000$ people a year are now using IELTS to initiate a new life in a foreign English speaking country. Over 6,000 educational institutions, government agencies, and professional organisations across 120 countries around the world, including over 2,000 institutions in the USA, recognize IELTS band scores for a range of purposes including further duration, training, and immigration (http://www.ieltstehran.com/index.php).

The following information retrieved from http://www .ielts.org/ shows a clear explanation about IETLS test results. IELTS is accredited by the regulatory authorities of external qualifications in England, Wales, and Northern Ireland for test results at bands $4 / 4.5,5 / 5.5,6 / 6.5$, and $7 / 7.5$. If IELTS bands 4 or 4.5 are reported, then the applicant named overleaf has achieved the Cambridge ESOL Entry Level Certificate in English. If IELTS bands 5 or 5.5 are reported, then the applicant named overleaf has achieved the Cambridge ESOL Level 1 Certificate in English. If IELTS bands 6 or 6.5 are reported, then the applicant named overleaf has achieved the Cambridge ESOL Level 2 Certificate in English. If IELTS bands 7 or 7.5 are reported, then the applicant named overleaf has achieved the Cambridge ESOL Level 3 Certificate in English. As with all IELTS testing, authentic academic and general contexts are a central feature of listening and reading tests, and a range of native speaker accents are used to record the lectures and dialogues.

7.3. Data Analysis. The current study used SPSS 17 for windows for the statistical analysis measures (i) an ANOVA, post hoc comparisons, and a pairwise correlation coefficient used to measure the correlation of four communicative macroskills, (ii) mean scores calculated for the applicants' performance in reading against other communicative macroskills, and (iii) a sequential regression analysis and a scatter plot used to measure whether listening skill was strongly correlated with overall English language proficiency. Multiple regressions analysis was chosen because it provides both the canonical correlation of the variables and the information about the unique contribution made by the explanatory variables [67].

\section{Results}

A summary of the IELTS scores analysis is presented in this section. Table 1 displays the descriptive statistics for each language skill. The mean (5.350) and standard deviation (.993) of speaking skill show the lowest attainment. In contrast, reading with the mean (6.679) and standard deviation (.797) shows the highest achievement. As indicated in Table 1, listening entailing the mean (5.514) and standard deviation (1.069) places one before the last skill: writing skill attainment with the mean (6.130) and standard deviation (.813). In brief, applicants' attainment of aural/oral skills was less than orthographic skills in IELTS, and the overall achievement of mean (5.987) and standard deviation (.790) is found in Table 1.

\subsection{Results by Research Question}

The First Research Question. Relationships among listening, speaking, reading, and writing skills in IELTS were examined using Pearson product-moment correlations. The following assumptions of correlation research were evaluated and found tenable prior to conducting the data analysis: (i) an ANOVA and (ii) post hoc comparisons. All assumptions of these analyses were found tenable and described below, and Pearson $\mathrm{r}$ correlation coefficients were computed too.

Results of the analysis presented in Table 2 show that all four categories of communicative macroskills are significantly correlated with one another. Also, listening has more significant correlation with reading $(r=.729)$ than writing $(r=.631)$ and speaking $(r=.629)$ skills. An equal but low significant correlation is found between reading/speaking and writing/speaking $(r=.498)$.

A one-way between-group analysis of variance (see Table 3) was conducted to explore the relationship between listening and speaking, reading and writing skills. There is a statistically significant difference at the $P \leq .05$ level in scores within three groups: $F(3,2800)=302.780, P=.000$.

IELTS' scores are divided into three categories: (i) listening in partnership with speaking, reading, and writing, (ii) speaking in relationship with reading and writing, and (iii) reading and writing. The post hoc comparisons using the Tukey honesty significant differences (HSDs) test in Table 4 indicate the mean difference for the three categories. For instance, the comparison between listening/reading and speaking/reading produces the biggest significant effect size $(-1.16548, P=.005$ and $-1.32953, P=.000)$, respectively, but listening/speaking yields the smallest significant effect size $(.16405, P=.005)$ as evidenced in Table 4 . The effect size of comparing reading/writing $(.54922, P=.000)$ is bigger than the effect size of listening/speaking $(.16405, P=.005)$. Also, listening has a bigger effect size with writing $(-.61626$, $P=.000)$ than speaking $(.16405, P=.005)$, but the effect 
TABLE 1: Descriptive analysis of all language skills.

\begin{tabular}{|c|c|c|c|c|c|c|}
\hline & $N$ & Mean & Std. deviation & Std. error & Minimum & Maximum \\
\hline Listening & 701 & 5.514 & 1.069 & .040 & 1.00 & 9.00 \\
\hline Speaking & 701 & 5.350 & .993 & .037 & 1.00 & 9.00 \\
\hline Reading & 701 & 6.679 & .797 & .030 & 3.50 & 9.00 \\
\hline Writing & 701 & 6.130 & .813 & .030 & 1.50 & 9.00 \\
\hline Overall & 701 & 5.987 & .790 & .029 & 3.00 & 9.00 \\
\hline
\end{tabular}

TABLE 2: $r$ Correlations among skills and overall score.

\begin{tabular}{lcccc}
\hline Categories & $\mathrm{A}$ & $\mathrm{B}$ & $\mathrm{C}$ & $\mathrm{D}$ \\
\hline Listening (A) & 1.00 & & & \\
Reading (B) & $.729^{* *}$ & 1.00 & & \\
Writing (C) & $.631^{* *}$ & $.591^{* *}$ & 1.00 & \\
Speaking (D) & $.629^{* *}$ & $.498^{* *}$ & $.498^{* *}$ & 1.00 \\
\hline
\end{tabular}

Note. ${ }^{* *}$ Correlation is significant at the 0.01 level ( 2 tailed).

TABLE 3: ANOVA.

\begin{tabular}{lccccc}
\hline & $\begin{array}{c}\text { Sum of } \\
\text { squares }\end{array}$ & df & $\begin{array}{c}\text { Mean } \\
\text { square }\end{array}$ & $F$ & Sig. \\
\hline $\begin{array}{l}\text { Between } \\
\text { groups }\end{array}$ & 778.672 & 3 & 259.557 & 302.780 & .000 \\
$\begin{array}{l}\text { Within } \\
\text { groups }\end{array}$ & 2400.289 & 2800 & .857 & & \\
\hline Total & 3178.961 & 2803 & & & \\
\hline
\end{tabular}

size of listening/writing $(-.61626, P=.000)$ is smaller than is the effect size of speaking/writing $(-.78031, P=.000)$.

The Second Research Question. To examine whether applicants' reading background contributed to higher attainments of reading skill than other skills in IELTS, descriptive analysis in Table 1 shows that applicants received the highest mean score $(M=6.679)$ and the least standard deviation (SD = .797) in the high stakes test of IELTS comparing with means and standard deviations of listening $(M=5.514, \mathrm{SD}=$ $1.069)$, speaking $(M=5.350, \mathrm{SD}=.993)$, and writing scores $(M=6.130, \mathrm{SD}=.813)$.

The Third Research Question. A correlation analysis was performed to determine whether listening skill was strongly correlated with the overall language proficiency. Four communicative macroskills (listening, speaking, reading, and writing) were specified as the predictor variables, with overall language proficiency as the criterion variable. The results of these correlation analyses showed in Table 5 that a close and strong correlation existed between listening and overall language proficiency $r$ values $(701)=.893, P=.000$, followed by reading/writing and overall language proficiency $r$ value $(701)=.792, P=.000$ as well as speaking and overall language proficiency $r$ value $(701)=.756, P=.000$. However, all four communicative macroskills had a high significant correlation above $r=.70$ [67] with the overall language proficiency in IELTS.

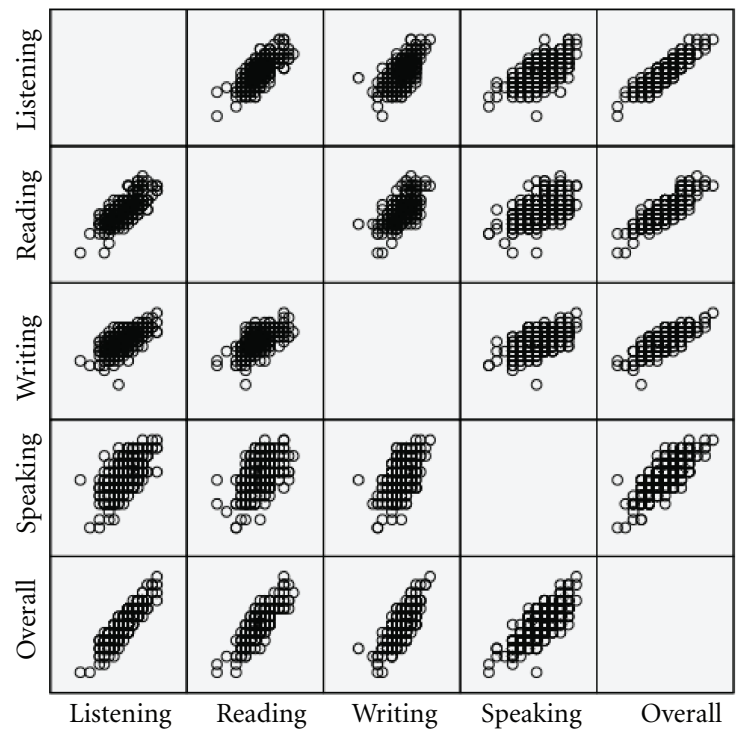

FIgURE 1: Scatter plot for individual and overall skill.

It was assumed from previous research that listening skill would be the most significant factor in overall language proficiency in a standard regression, so a sequential regression was run to examine the effects of other variables before speaking skill was added. The variable of listening skill measures added the most explanatory power to the model $1\left(\Delta R^{2}=.797\right)$ when it was added before speaking skill. After all the other three variables were added, speaking skill accounted for $.04 \%$ of the variance, but it was the only statistical variable in the regression model with all four explanatory variables. Total $R^{2}$ for the model, change in $R^{2}$, and unstandardized regression coefficient $(\beta)$ and their $P$ values are found in Table 6 below. Model 4, with all four predictors, accounted for $97 \%$ of the insignificant variance in overall language proficiency like other skills. Certainly, listening skill, with $80 \%$ of insignificant variance, is the most important but least variable for predicting overall language proficiency performance.

Listening skill has $90 \%$ correlation with overall language proficiency. As such, in view of the fact that the performance of individual and overall skill scores in scatter plot here demonstrates the extent to which variables are correlated. As illustrated in Figure 1, all communicative macro skill scores have a positive correlation with each other. Unlike speaking skill having the least correlation with the overall score, listening skill has the closest correlation with the overall score. 
TABle 4: One-way ANOVA: post hoc.

\begin{tabular}{lcccc}
\hline Categories & Categories & Mean difference & Std. error & Sig. \\
$(I)$ & $(J)$ & $(I-J)$ & .04945 & .005 \\
\hline \multirow{2}{*}{ Listening } & Speaking & $.16405^{*}$ & .04945 & .000 \\
& Reading & $-1.16548^{*}$ & .04945 & .000 \\
& Writing & $-.61626^{*}$ & .04945 & .000 \\
Speaking & Reading & $-1.32953^{*}$ & .04945 & .000 \\
Reading & Writing & $-.78031^{*}$ & .04945 & .000 \\
\hline
\end{tabular}

Note. ${ }^{*}$ The mean difference is significant at the 0.05 level.

TABle 5: Reporting of $r$ value, $P$ value, and $N$ between overall and individual skill.

\begin{tabular}{lcccc}
\hline & Listening & Writing & Reading & Speaking \\
\hline Overall & $.893^{* *}$ & $.792^{* *}$ & $.792^{* *}$ & $.756^{* *}$ \\
$P$ value & .000 & .000 & .000 & .000 \\
$N$ & 701 & 701 & 701 & 701 \\
\hline
\end{tabular}

Note. ${ }^{* *}$ Correlation is significant at the 0.01 level ( 2 tailed).

As a result of the close correlation, the higher the listening skill score, is the higher the overall IELTS score leads to a higher language proficiency in EFL language.

\section{Discussion and Conclusion}

This study investigated the links among four communicative macroskills used in the high stakes test (IELTS) performance of those applicants living in a country where English language has no acknowledgement in the society but used as a subject in schools. With regard to the first assumption, the extent to which the cycle of communicative macroskills, such as listening, speaking, reading, and writing, has in common in terms of language proficiency, the commonality of macroskills in the cycle is significantly positive but varied in proportion. The results displayed that listening and reading skills had the highest correlation, but reading and writing skills had the least correlation. The finding regarding the close relationship between listening and reading is consistent with the results of some previous studies that have shown the share of their basic cognitive processes in language learning $[33,38,39,41,42]$. However, some [5052] unanimously agree with the dissimilarity of listening and reading skills in terms of the receiving input to process the data. They also suggest that listeners have a limited access to the stream of input as opposed to readers having access to the text input to assess their understanding when needed. Thus, the finding supports the notion of developing the structure of productive skills (speaking/writing) is required to foster the receptive skills (listening/reading) from the onset of learning.

However, a close correlation was found between listening and speaking as well as writing skill, and this finding provided support for the studies $[59,65]$ demonstrating the expansion of writing relied upon oral/aural skill which led to consciousness and awareness. With regard to the second assumption that the applicants' reading background assists them in performing better in reading than other skills, the result also verified the assumption. The findings demonstrated that applicants had the highest mean score in reading and writing comparing with other communicative macroskills, for example, oral/aural. In contrast, listening and speaking skills received the least attainment. The finding of this study is consistent with Buck [55] suggesting that the complexity of listening is more than reading in terms of cognitive load processing input and aligns with Vandergrift [42] approving that listeners must make sense of linguistic and nonlinguistic attribution to understand the oral input.

Returning to the highest attainment in reading and writing skills, however, there might be several reasons for such findings. One basic reason might be the pedagogy cycle focusing on grammar translation method (GTM) used during middle and high schools in Iran. The premise of the traditional approach was to foster reading and writing skills in learning EFL so that students would be able to read the literature in the target language. Dörnyei [68] maintained that focusing on the situation contributes significantly to the motivation of a particular task. This opinion aligns with applicants in this study who benefit from reading skill in English at middle and high schools and college as a subject. The finding of this study supports the fact that the context is an important element influencing language learning. This could not be seen as a surprising result showing that applicants, due to being devoid of English language exposure in Iran, attained aural/oral skill less than orthographic and expressive skills in this study. Another reason might be the reading strategies applied in classrooms that assisted the applicants in performing better in reading/writing than speaking/listening in IELTS, whilst listening and speaking were overlooked in the pedagogy during school period.

The result of this study confirms Hulstijn's [69] argument in psycholinguistic perspectives in that having access to basic knowledge of vocabulary stored in long-term memory contributes learners to the systematic rehearsal and other cognitive strategies. Previous research has showed that middle eastern in general and Iranian learners in particular are medium bordering on high learning strategy users. Riazi and Rahimi [70], for example, found that Iranian EFL learners were "medium" strategy users overall, while with regard to strategy categories, they used metacognitive strategies with a high frequency; cognitive, compensation, and affective 
TABLE 6: Sequential regression analysis examining the relationship of macro skills and overall language proficiency.

\begin{tabular}{|c|c|c|c|c|c|c|}
\hline Model & Total $R^{2}$ & $\Delta R^{2}$ & Listening $(\beta)$ & Writing $(\beta)$ & Reading $(\beta)$ & Speaking $(\beta)$ \\
\hline 1 & .797 & .797 & $.893(.000)$ & & & \\
\hline 2 & .884 & .087 & $.658(.000)$ & $.380(.000)$ & & \\
\hline 3 & .924 & .044 & $.467(.000)$ & $.311(.000)$ & $.315(.000)$ & \\
\hline 4 & .968 & .040 & $.332(.000)$ & $.268(.000)$ & $.311(.000)$ & $.262(.000)$ \\
\hline
\end{tabular}

strategies with a medium frequency; memory and social strategies with a low frequency (e.g., [71]). In this study, despite lack of strategy intervention, the finding can guarantee a launching pad for future studies to apply learning strategies for each of the four communicative macroskills to facilitate the power of language learning outcomes.

As a rule of thumb, it is beyond expectation for a language learner to outperform listening and speaking in a context where language is not spoken other than communication in the classroom, noted earlier. Next, all applicants attended language preparation classes where communicative approach was in practice and focused equally on teaching four communicative macroskills. However, they achieved the highest attainment in reading, due to having lengthier history of reading practice. Thus, there might be another factor, such as practising writing traditionally in and out of classroom in school as well as practising in communicative approach classroom as a preparation course for IELTS. The finding shows that there is a moderate correlation between reading and writing skills which is consistent with the finding of Berninger et al.'s [72] study. The mediation between the macroskills can be an effective factor and hence should be considered when researching, designing classroom curricula, and using learning strategies to foster language learning in the classroom. All these suggest that taking all communicative macroskills into account basically drives learners home but not treating one separately since the finding showed a moderate and high correlation/interdependency among them.

With regard to the third assumption that listening skill has a stronger correlation with the overall language proficiency than other skills, the result is affirmative. Listening skill is the basic bricks and mortar of language acquisition. Based on the results of the study, the correlation coefficients confirmed this prediction. The correlation between listening skill and other language skills: speaking, reading, and writing as well as overall IELTS scores is large. Despite a close relationship between aural/oral skills in nature, the correlation between listening and reading attainment, however, was stronger than the attainment of listening, and speaking skills. Writing is the last skill learned by first and second language learners. However, the correlation between listening and writing scores is moderate but larger than the correlation between listening and speaking. Thus, reading, due to its common cognitive features with listening, had the highest correlation attainment in the applicants' IELTS scores.

Given that I found many studies $[58,73]$ showing the multiple influences of listening in primary and secondary language learning, the outcome of this study posits that listening skill has a large correlation with EFL proficiency.
Emphasizing the relationship between listening and writing skill, one starts acquiring listening at birth but writing at school age in first language; the EFL test result confirms the core of Shanahan's [59] discussion about the impact of listening skill instruction on writing development. The multiple correlations in the current study focused on one dependent variable: listening and three independent variables: speaking, reading, and writing as well as overall scores accounting for interrelationship of the independent variables. The analysis produced multiple coefficient of $(r=0.893, P \leq .000)$. This result is remarkably high to consider the importance of listening skill in EFL classrooms. In the end, the finding that the higher the listening score, the better the speaking also supports James [32] and Rost's [26] research suggesting that listening skill plays essential roles to improve speaking skill.

In conclusion, the findings of this study contributed to the research treating the pedagogy cycle of each language skill for the purpose of developing second or foreign language learning. The findings demonstrate that all four communicative macroskills have a moderate correlation leading to enhance language learning, though the correlation of binary skills was varied from low moderate (reading and writing) to high (listening and reading). Of the four communicative skills, the applicants had further learning experience in reading during school period led to the mounting attainment in the high stakes test. In this study, listening which is considered an overlooked skill in ESL/EFL settings showed a strong correlation with the overall language proficiency. There is no magic formula to foster language learning, but the findings of this study suggest that taking all communicative macroskills into account continues to capitalize the strength of language learning and maximizes and promotes particularly the cycle of second/foreign language pedagogy in the classroom.

\section{References}

[1] W. Grabe, "Reading in a second language," in Oxford Handbook of Applied Linguistics, R. B. Kaplan, Ed., pp. 49-59, Oxford University Press, Oxford, UK, 2002.

[2] I. Leki, "Second language writing," in Oxford Handbook of Applied Linguistics, R. B. Kaplan, Ed., pp. 60-69, Oxford University Press, Oxford, UK, 2002.

[3] M. Bygate, "Speaking," in Oxford Handbook of Applied Linguistics, R. B. Kaplan, Ed., pp. 27-38, Oxford University Press, Oxford, UK, 2002.

[4] C. Goh, "Metacognitive instruction for second language listening development: theory, practice and research implications," RELC Journal, vol. 39, no. 2, pp. 188-213, 2008.

[5] T. Lynch, "Listening: questions of level," in Oxford Handbook of Applied Linguistics, R. B. Kaplan, Ed., pp. 39-47, Oxford University Press, Oxford, UK, 2002. 
[6] L. Vandergrift, "Recent development in second and foreign language listening comprehension research," Language Teaching, vol. 40, pp. 191-210, 2007.

[7] J. Hartley, "Reading, writing, speaking and listening: perspectives in applied linguistics," Applied Linguistics, vol. 28, no. 2, pp. 316-320, 2007.

[8] R. A. Hunsaker, Understanding and Developing the Skills of Oral Communication: Speaking and Listening, J. Morton Press, Englewood, Colo, USA, 2nd edition, 1990.

[9] D. L. Linebarger, "Beginning literacy with language: young children learning at home and school," Topics in Early Childhood Special Education, vol. 21, pp. 188-192, 2001.

[10] T. Morris and G. Leavey, "Promoting phonological awareness in nursery-aged children through a Sure Start Early Listening programme," International Journal of Early Years Education, vol. 14, no. 2, pp. 155-168, 2006.

[11] E. Hinkel, "Building awareness and practical skills for crosscultural communication in ESL/EFL", in Teaching English as a Second or Foreign Language, M. Celce-Murcia, Ed., pp. 443458, Heinle \& Heinle, Boston, Mass, USA, 3rd edition, 2001.

[12] E. Hinkel, "Current perspectives on teaching the four skills," TESOL Quarterly, vol. 40, no. 1, pp. 109-132, 2006.

[13] M. B. Gilbert, "An examination of listening effectiveness of educators: performance and preference," Professional Educator, vol. 27, no. 1/2, pp. 1-16, 2005.

[14] N. A. Badian, "Reading disability defined as a discrepancy between listening and reading comprehension: a longitudinal study of stability, gender differences, and prevalence," Journal of Learning Disabilities, vol. 32, no. 2, pp. 138-148, 1999.

[15] O. Bergman, "Wait for me! Reader control of narration rate in talking books," International Reading Association's Reading Online 1999, http://www.readingonline.org/articles/art_index .asp?HREF=/articles/bergman/index.html.

[16] V. W. Berninger, "Development of language by hand and its connections to language by ear, mouth and eye," Topics in Language Disorders, vol. 20, no. 4, pp. 65-84, 2000.

[17] T. P. Rankin, "The measurement of the ability to understand spoken language," Language Journal, vol. 78, pp. 199-221, 1926.

[18] G. N. Ralph and L. S. Stevens, Are You Listening? McGraw-Hill, New York, NY, USA, 1957.

[19] P. T. Rankin, "Listening ability: its importance, measurement, and development," Chicago Schools Journal, pp. 147-179, 1930.

[20] S. Voncile, "A beginning, and an editor anticipates," Journal of the International Listening Association, vol. 1, pp. 1-2, 1987.

[21] C. M. Feyten, "The power of listening ability: an overlooked dimension in language acquisition," The Modern Language Journal, vol. 75, no. 2, pp. 173-180, 1991.

[22] R. Steven, "A study of effective and ineffective listening dyads using the systems theory principle of entropy," Journal of the International Listening Association, vol. 1, pp. 32-53, 1987.

[23] A. Wolvin and C. Carolyn, Listening, Brown, Dubuque, Iowa, USA, 1988.

[24] J. Floyed, Listening a Practical Approach, Scott Foreswan and Company, Glenview, Ill, USA, 1985.

[25] J. Field, "Bricks or mortar: which parts of the input does a second language listener rely on?" TESOL Quarterly, vol. 42, no. 3, pp. 411-432, 2008.

[26] M. Rost, Introducing Listening, Renguin Group, London, UK, 1994.

[27] A. Luke, "On writing: an autotheoretic account," in Culture and Identity in Language Learning and Use: A Microethnographic Approach, C. Julie and D. Nunan, Eds., Routledge, New York, NY, USA, 2009.
[28] J. Blommaert, Discourse: A Critical Introduction, Cambridge University Press, Cambridge, UK, 2005.

[29] J. L. Lantolf and S. L. Thorne, Sociocultural Theory and the Genesis of Second Language Development, Oxford University Press, Oxford, UK, 2006.

[30] M. Hoey, "Some properties of spoken discourses," in Applied Linguistics and English Language Teaching, R. Bowers and C. J. Brumfit, Eds., pp. 65-84, Modern English Publications in association with the British Council, London, UK, 1991.

[31] N. Shameem and M. Tickoo, New Ways in Using Communicative Games in Language Teaching, New Ways in TESOL Series II: Innovative Classroom Techniques: ERIC, 1999.

[32] C. J. James, "The testing of proficiency in listening comprehension: guiding for teaching," In a meeting the call for excellence in the foreign language classroom and selected papers from the Central States Conference on the Teaching of Foreign Languages, 1985.

[33] P. D. Pearson and L. Fielding, "Comprehension instruction," in Handbook of Reading Research, R. Bar, M. L. Kamil, and P. B. Mosenthal, Eds., vol. 2, pp. 815-860, Longman, New York, NY, USA, 1991.

[34] V. Harris, A. Gaspar, B. Jones et al., Helping Learners Learn: Exploring Strategy Instruction in Language Classrooms across Europe, European Centre for Modern Languages, Graz, Austria, 2001.

[35] J. S. Chall, Learning to Read: The Great Debate, Harcourt Brace, Fort Worth, Tex, USA, 1967.

[36] C. A. Perfetti, Reading Ability, Oxford University Press, New York, NY, USA, 1985.

[37] F. R. Vellutino and D. M. Scanlon, "Phonological coding, phonological awareness and reading ability: evidence from a longitudinal and experimental study," Merrill-Palmer Quarterly, vol. 33, pp. 321-363, 1987.

[38] J. Bae and L. F. Bachman, "A latent variable approach to listening and reading: testing factorial invariance across two groups of children in the korean/English two-way immersion program," Language Testing, vol. 15, no. 3, pp. 380-414, 1998.

[39] G. P. Park, "Comparison of L2 listening and reading comprehension by university students learning English in Korea," Foreign Language Annals, vol. 37, no. 3, 2004.

[40] S. J. Samuels, "Factors that influence listening and reading comprehension," in Comprehending Oral and Written Language, R. Horowitz and S. J. Samuels, Eds., pp. 295-325, Academic Press, San Diego, Calif, USA, 1987.

[41] L. Vandergrift, "Listening to learn or learning to listen?" Annual Review of Applied Linguistics, vol. 24, pp. 3-25, 2004.

[42] L. Vandergrift, "Second language listening: listening ability or language proficiency?" Modern Language Journal, vol. 90, no. 1, pp. 6-18, 2006.

[43] G. R. Kiany and E. Shiramiry, "The effect of frequent dictation on the listening comprehension ability of elementary EFL learners," TESL Canada Journal, vol. 20, pp. 57-63, 2002.

[44] A. S. Hasan, "Learners' perceptions of listening comprehension problems," Language, Culture and Curriculum, vol. 13, no. 2, 2000 .

[45] C. Mareschal, Student perceptions of a self-regulatory approach to second language listening comprehension development [Ph.D. thesis], University of Ottawa, Ottawa, Canada, 2007.

[46] C. Goh and Y. Taib, "Metacognitive instruction in listening for young learners," English Language Teachers Journal, vol. 60, no. 3, pp. 222-232, 2006.

[47] L. J. Zhang and A. Wu, "Chinese senior high school EFL students' metacognitive awareness and reading-strategy use," Reading in a Foreign Language, vol. 21, no. 1, pp. 37-59, 2009. 
[48] R. C. Gardner, A. M. Masgoret, J. Tennant, and L. Mihic, "Integrative motivation: changes during a long intermediate level language course," Language Learning, vol. 54, no. 1, pp. $1-34,2004$.

[49] B. Linda and L. A. Brown, "Metacognitive skills and reading," in Handbook of Reading Research, P. D. Pearson, M. Kamil, R. Barr, and P. Mosenthal, Eds., pp. 353-394, Longman, New York, NY, USA, 2002.

[50] L. T. Dipper, M. Black, and K. L. Bryan, "Thinking for speaking and thinking for listening: the interaction of thought and language in typical and non-fluent comprehension and production," Language and Cognitive Processes, vol. 20, no. 3, pp. 417-441, 2005.

[51] I. Thompson, "Assessment of second/foreign language listening comprehension," in A Guide for the Teaching of Second Language Listening, D. Mendelsohn and J. Rubin, Eds., pp. 3158, Dominie Press, San Diego, Calif, USA, 1995.

[52] J. Brown, "Listening-ubiquitous yet obscure," Journal of the International Listening Association, vol. 1, pp. 3-14, 1987.

[53] J. Sweller, "Cognitive bases of human creativity," Educational Psychology Review, vol. 21, no. 1, pp. 11-19, 2009.

[54] A. C. S. Chang and J. Read, "Support for foreign language listeners: its effectiveness and limitations," RELC Journal, vol. 38, no. 3, pp. 375-394, 2007.

[55] G. Buck, Assessing Listening, Cambridge University Press, Cambridge, UK, 2001.

[56] E. H. Jung, "The role of discourse signalling cues in second language listening comprehension," The Modern Language Journal, vol. 87, no. 4, pp. 562-577, 2003.

[57] J. K. Swaffar and S. M. Bacon, "Reading and listening comprehension: perspectives on research and implications for practice," in Research in Language Learning: Principles, Processes, and Prospects, A. H. Omaggio, Ed., pp. 124-155, National Textbook, Lincolnwood, Ill, USA, 1993.

[58] J. C. Richards, "Second thoughts on teaching listening," RELC Journal, vol. 36, no. 1, pp. 85-92, 2005.

[59] T. Shanahan, "Relations among oral language, reading and writing development," in Handbook of Writing Research, A. C. MacArthur, S. Graham, and J. Fitzgerald, Eds., The Guidford Press, 2006.

[60] B. S. Wood, Children and Communication: Verbal and Nonverbal Language Development, Prentice-Hall, Englewood Cliffs, NJ, USA, 2nd edition, 1981.

[61] F. Yalcinkaya, N. B. Muluk, and S. Sahin, "Effects of listening ability on speaking, writing and reading skills of children who were suspected of auditory processing difficulty," International Journal of Pediatric Otorhinolaryngology, vol. 73, no. 8, pp. 1137-1142, 2009.

[62] E. Semel, E. H. Wiig, and W. A. Secord, Clinical Evaluation of Language Fundamentals, Psychological Corporation, San Antonia, Tex, USA, 4th edition, 2003.

[63] A. T. Cacace and D. J. McFarland, "Central auditory processing disorder in school-aged children: a critical review," Journal of Speech, Language, and Hearing Research, vol. 41, no. 2, pp. 355-373, 1998.

[64] V. L. Harris, R. W. Keith, and K. K. Novak, "Relationship between two dichotic listening tests and the Token test for children," Ear and Hearing, vol. 4, no. 6, pp. 278-282, 1983.

[65] V. W. Berninger, R. D. Abbott, J. Jones et al., "Early development of language by hand: composing, reading, listening, and speaking connections; three letter-writing modes; and fast mapping in spelling," Developmental Neuropsychology, vol. 29, no. 1, pp. 61-92, 2006.
[66] P. B. Nayar, "ESL/EFL dichotomy Today: language politics or pragmatics?” TESOL Quarterly, vol. 31, no. 1, pp. 9-37, 1997.

[67] B. G. Tabachnick and L. S. Fidell, Using Multivariate Statistics, Allyn \& Bacon, Boston, Mass, USA, 4th edition, 2001.

[68] Z. Dörnyei, Motivational Strategies in the Language Classroom, Cambridge University Press, Cambridge, UK, 2001.

[69] J. H. Hulstijn, "Intentional and incidental second language vocabulary learning: a reappraisal of elaboration, rehearsal and automaticity," in Cognition and Second Language Instruction, P. Robinson, Ed., pp. 258-286, Cambridge University Press, Cambridge, UK, 2001.

[70] A. Riazi and M. Rahimi, "Iranian EFL learners' pattern of language learning strategy use," The Journal of Asia TEFL, vol. 2, no. 1, pp. 103-129, 2005.

[71] A. Riazi, "Language learning strategy use: perceptions of female Arab english majors," Foreign Language Annals, vol. 40, no. 3, pp. 433-440, 2007.

[72] V. W. Berninger, R. D. Abbott, S. P. Abbott, S. Graham, and T. Richards, "Writing and reading: connections between language by hand and language by eye," Journal of Learning Disabilities, vol. 35, no. 1, pp. 39-56, 2002.

[73] R. Ellis, The Study of Second Language Acquisition, Oxford University Press, Oxford, UK, 1994. 

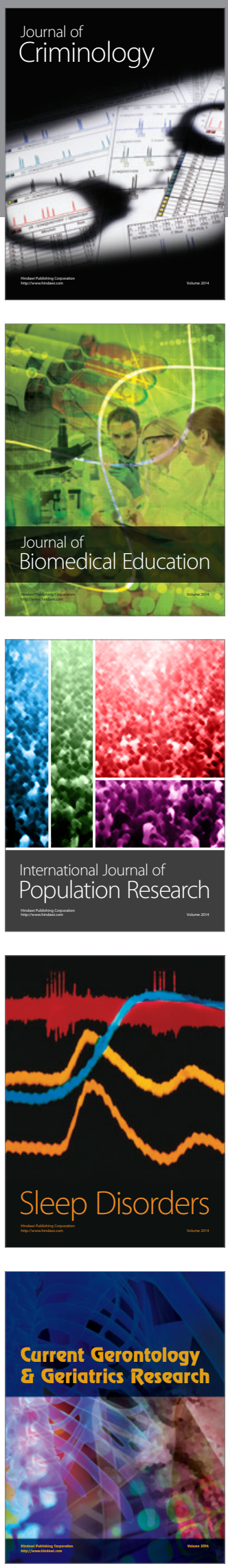


Submit your manuscripts at

http://www.hindawi.com

Child Development Research
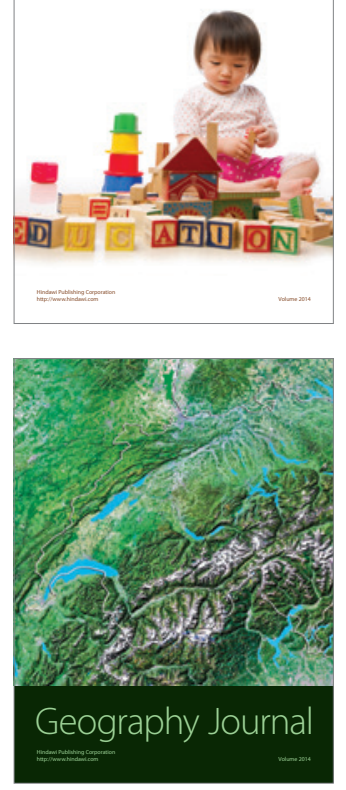

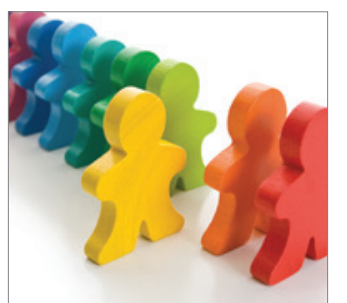

Autism

Research and Treatment

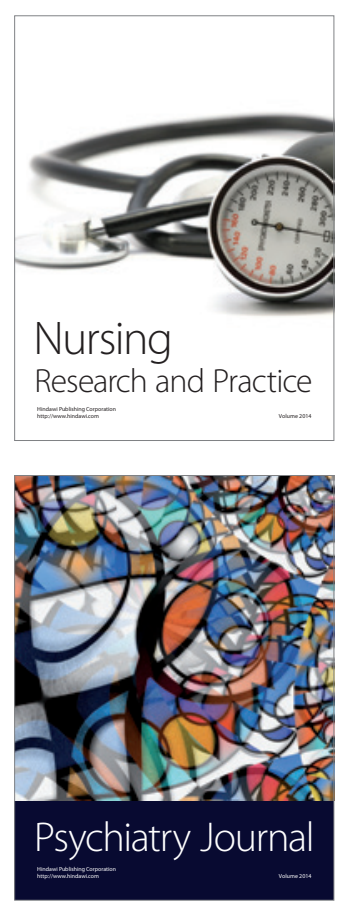
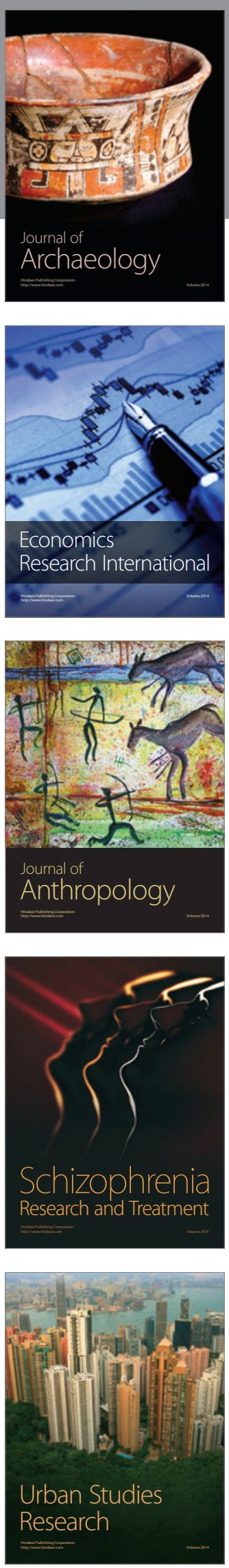